Interactive comment on "A global gridded $\left(0.1^{\prime}, \times 0.1\right)$ inventory of methane emissions from oil, gas, and coal exploitation based on national reports to the United Nations Framework Convention on Climate Change" by Tia R. \title{
Scarpelli et al.
}

Tonatiuh Guillermo Nuñez Ramirez

tnunez@bgc-jena.mpg.de

Received and published: 17 October 2019

I have only a few issues for the main text:

- Assuming a normal distribution, the $95 \%$ confidence interval has a range of $4-\sigma$ $( \pm 2-\sigma)$.

- Allocating the errors from national scale to gridcell scale should be done taking 
care of uncertainty propagation. This is always very unclear in other studies so I believe consistency between the national and gridcell scale are very important.

- It would be useful to include uncertainty estimates in table 2 (both for normal and log-normal distributions).

- The information for coal seems to be a stump. It would very useful if you would include separate emissions for underground and surface mining, post mining operations and type of coal (at least lignite vs bituminous or anthracite) as these data can be of use for isotope studies, e.g. Zazzerri et al. (2016)

- Figure 2: it would be useful to also see locations of refineries, storage stations, gas processing stations, etc.

- Figure 3: Comparison to other inventories would be useful. As would be maybe a latitudinal profile of emissions between the different inventories.

One of the main novel issues of these study is the more transparent use of an array of databases is used to spatially allocate national emissions to infrastructure including wells, pipelines, oil refineries, gas processing plants, gas compressor stations, gas storage facilities, and coal mines. However, when looking at the netcdf data explicitly, I found a number of inconsistencies in the allocation of emissions:

- Emissions from gas processing (both flaring and fugitive emissions) where allocated to pipelines in Eurasia, Northern Africa, and South America. For flaring, there is no data for the US.

- Emissions from gas storage in North America and parts of Asia are also distributed to pipelines.

- Emissions from venting during gas transmission is not given for several countries including Russia and the US, which are the most important in this sector. 
- Emissions from oil refining and transport in North America were allocated to oil fields and not to the actual refineries location or pipelines. The emissions from oil tankers found in EDGAR are not found in this inventory.

- Coal emissions in Japan, Netherlands and Ireland are distributed according to population, whereas the location of such mines are quite specific in these countries, e.g. https://en.wikipedia.org/wiki/List_of_mines_in_Ireland, https: //www.tudelft.nl/en/ceg/about-faculty/departments/geoscience-engineering/ sections/resource-engineering/links/coal-mining-in-the-netherlands/ and https://en.wikipedia.org/wiki/List_of_coal_mines_in_Japan.

- No distinction seems to be made between oil and gas wells and pipelines, such that the distribution production emissions from both types of fossil fuels is very similar.

From my own research I can point to several other datasets that help with the allocation of emissions:

- Flaring

- The radiant output of gas flares contained in the Worldwide natural gas flaring dataset [http://skytruth.org/viirs/] (free data but only for one year).

- The gold standard would be the data from Elvidge et al. $(2007,2009,2012)$ but it seems not to be publicly available.

- Oil storage: https://tankterminals.com

- Oil pipelines: http://worldmap.harvard.edu/data/geonode:global_oil_pipelines_ $7 z 9$

- Refineries: Oil \& Gas Journal periodic Worldwide Refining Survey 
- Oil vs Gas fields:

- Petroleum Dataset v. 1.2 (Lujala, 2007)

ESSDD

- Giant Oil and Gas Fields of the World database (Horn, 2004)

- US shale plays (EIA, 2011)

Interactive

comment

\section{References:}

Elvidge, C., Baugh, K. E., Tuttle, B. T., Howard, A. T., Pack, D. W., Milesi, C., Erwin, E. H. (2007). A Twelve Year Record of National and Global Gas Flaring Volumes Estimated Using Satellite Data (pp. 1-107). World Bank.

Elvidge, C. D., Ziskin, D., Baugh, K. E., Tuttle, B. T., Ghosh, T., Pack, D. W., et al. (2009). A Fifteen Year Record of Global Natural Gas Flaring Derived from Satellite Data. Energies, 2(3), 595-622. http://doi.org/10.3390/en20300595

Elvidge, C., Zhizhin, M., Baugh, K. E., Hsu, F.-C., Ghosh, T. (2016). Methods for Global Survey of Natural Gas Flaring from Visible Infrared Imaging Radiometer Suite Data. Energies, 9(1), 14. http://doi.org/10.3390/en9010014

Horn, M. K. (2004). Selected Features of Giant Fields, Using Maps and Histograms. American Association of Petroleum Geologist Search and Discovery, 1-14. Retrieved from http://www.searchanddiscovery.com/documents/2004/horn/index.htm

Lujala, P., d, J. R., Thieme, N. (2007). Fighting over Oil: Introducing a New Dataset. Conflict Management and Peace Science, 24(3), 239-256. http://doi.org/10.1080/07388940701468526

US Energy Information Adminstration, I. S. A. (2011, May 9). North American shale plays. International Energy Statistics. Retrieved from https://www.eia.gov/maps/maps.htmgeodata

Zazzeri, G., Lowry, D., Fisher, R. E., France, J., Lanoisellé, M., Kelly, B. F. J., et al. 
(2016). Carbon isotopic signature of coal-derived methane emissions to atmosphere: from coalification to alteration. Atmospheric Chemistry and Physics, 16, 13669-13680.

ESSDD http://doi.org/10.5194/acp-16-13669-2016

Interactive comment on Earth Syst. Sci. Data Discuss., https://doi.org/10.5194/essd-2019-127, 2019.

Interactive

comment 